\title{
Foley Catheter
}

National Cancer Institute

\section{Source}

National Cancer Institute. Foley Catheter. NCI Thesaurus. Code C54730.

A flexible plastic tube inserted into the bladder to provide continuous urinary drainage. A balloon on the bladder end is inflated (with air or fluid) so that the catheter cannot pull out but is retained in the bladder as an "indwelling" catheter. 